DOI: $10.17805 / z p u .2015 .3 .33$

\title{
Проблема жанровой классификации фэнтези как вида приключенческой литературы
}

\author{
И. В. ЛЕБЕДЕВ \\ (МОСКОВСКИЙ ГОСУДАРСТВЕННЫЙ ГУМАНИТАРНЫЙ УНИВЕРСИТЕТ \\ им. М. А. ШолОхОВА)
}

В статье рассматривается проблема жанровой классификации современного русскоязычного фэнтези. Автор указывает на попытки классифицировать фэнтези по проблемно-тематическому принципу, а также на основе функций искусства, выделенных М. С. Каганом; указываются недостатки данных подходов. Предлагается применить генетико-типологический принцип, который базируется на изучении развития приключенческих жанров вообще. Этот подход представляется наиболее естественным, поскольку фэнтези является новым этапом в развитии приключенческой литературы.

Современное фэнтези синтезирует два основных вида приключений, а именно приключение географическое и историческое. Роман «путешествий» вроде робинзонады сливается с историческим авантюрным романом. Таким образом, героическое фэнтези как бы «стягивает» обратно разветвившиеся жанровые подвиды. На этом направлении можно выделить соответственно в русской современной литературе: фэнтези «меча и магии» («Хранитель мечей» Н. Перумова; «Волкодав» М. Семеновой); историческое и псевдоисторическое фэнтези («Небеса ликуют» А. Валентинова, “Отблески Этерны» В. Камши); «воровское» или «разбойничье» фэнтези («Хроники Сиалы» А. Пехова), которое наследует пикареске и «разбойничьему» роману. Любовный роман дает любовное фэнтези («Анахрон» В. Беньковского и Е. Хаецкой); в области криминального романа мы видим зарождение детективного фэнтези («Под знаком мантикоры», «Пересмешник» А. Пехова»). Готический роман порождает все разновидности «черного» фэнтези ( Странствия Сенора» А. Дашкова, «Ночной смотрящий» О. Дивова), а научная фантастика - «научное» фэнтези или техномагию («Тайный Город» В. Панова). И наконец, социально-приключенческий роман при появлении мифологически-сказочных посылок дает тот вид фэнтези, который в современной издательской практике принято называть городским (цикл «Дозоры» С. Лукьяненко).

Типология показывает, что собственно фэнтезийные жанры не обнаруживают существенной самостоятельности; все они являются лишь новым этапом в развитии единого приключенческого метажанра. Заметно, что наибольшая активность наблюдается на том направлении, где фэнтезийная предпосылка является органически-естественной. Напротив, любовная и криминальная линии изначально обладают другим набором интенций, и фэнтезийная составляющая не может выступить в них на первый план, не исказив тем самым природу жанрового саспенса.

Ключевые слова: русское фэнтези, приключенческая литература, жанр, метажанр, жанровая классификация.

\section{ВВЕАЕНИЕ}

овременное русское фэнтези, несмотря на свою молодость, не является жанрово однородным. Его количественное и качественное многообразие зачастую затрудняет классификацию. И это естественно. Приключенческий метажанр (или «большой жанр») также не имеет общепризнанной классификации, хотя существует несравнимо дольше.

В 2007 г. в статье «Жанр фэнтези: проблема классификации» Е. Афанасьева свела воедино несколько попыток типизировать фэнтезийные поджанры, предпринятых ее предшественниками (Шидфар, 1997; Алексеев, Батшев, 1997; Ковтун, 1999; Невский, 2004: Электронный ресурс). Исследовательница обратила внимание на то, что основа- 
нием деления чаще всего выступает проблемно-тематический принцип. Обобщив идеи предшественников, Е. Афанасьева высказала новое соображение: по ее мнению, типологию фэнтезийных жанров следует проводить, основываясь на общей классификации искусства, предложенной М. С. Каганом (Каган, 1972). После скромных тематических делений это был довольно широкий замах. Опираясь на функции искусства, Е. Афанасьева предложила следующее деление фэнтези: по сюжетному принципу выделяется эпическое, романтическое, мистическое, «черное», мифологическое фэнтези; по национальной специфике «фэнтезийный мир строится на основе традиций какой-то определенной культуры» (кельтской, монгольской, скандинавской, славянской и т. А.); по времени действия можно выделить историческое и псевдоисторическое фэнтези, городское (современное) фэнтези, а также далекое будущее; в аксиологической плоскости «существуют 2 крайних полюса: с максимально положительной оценкой и “сатирические”, отрицающие: юмористическая, героическая фэнтези; в мировоззренческом аспекте можно выделить христианское или сакральное фэнтези, техномагию (она же научное фэнтези) и философский боевик (Афанасьева, 2009: 91). Самым последним признаком деления у Е. Афанасьевой выступает адресат, но здесь все традиционно: фэнтези делится на взрослое и крайне малочисленное детское.

Аанная классификация, на наш взгляд, слишком широкая. Например, вряд ли уместно говорить о национальном колорите так называемого славянского фэнтези: «славянство» в данном случае не более чем экзотическая декорация для приключения в той же степени, как отсылки к кельтскому, монгольскому или скандинавскому колориту. При всей осведомленности некоторых авторов в традициях национальных культур эти последние не более чем фон для авантюрного повествования. Что касается аксиологического модуса, то здесь тоже таится проблема: стоит ли относить сатирический или юмористический роман к фэнтези, даже если в них использовано множество «сказочных» допущений? Также возникают вопросы о мировоззренческой составляющей: например, техномагия - разве не может она быть христианской? И чем научное фэнтези отличается от фэнтези, действие которого разворачивается в далеком или не столь далеком будущем?

Все эти вопросы заставляют вернуться к поиску основного дифференцирующего признака и поискать менее широкое основание для классификации.

\section{ПРОБАЕМА ЖАНРА \\ В ПРИКАЮЧЕНЧЕСКОЙ АИТЕРАТУРЕ}

Представляется, что в качестве еще одного подхода можно исподьзовать генетикотипологический подход, а именно проследить трансформацию старых жанров приключенческой литературы в современное фэнтези.

Ставя проблему определения приключенческого метажанра, А. Вулис в свое время писал: «Приключенческое становится чем-то более общим, нежели жанр или даже сумма жанров, - оно становится способом художественного подхода к жизни» (Вулис, 1986: 22). «Поэтика приключенческой литературы едина... Приключенческая литература - некий наджанровый жанр, большой жанр. Он имеет свою поэтику, только модифицируемую от жанра к жанру, а не изобретаемую всякий раз заново» (там же: 26).

Вероятно, самой первой попыткой представить типологию приключенческого метажанра в отечественной науке была статья «Авантюрный роман», напечатанная в «Аитературной энциклопедии» 1925 г. Автор статьи А. Благой осветил в ней разви- 
тие романа приключений с момента его зарождения до современного состояния, обозначив те исторические модификации, которые возникали в ходе долгого исторического развития. Ученый последовательно выделяет эллинистический роман, рыцарский, а также средневековые любовные повести, типа «Окассен и Николетт». На излете Средневековья появился первый роман в современном понимании этого термина - авантюрный рыцарский эпос об Амадисе Галльском, который, в свою очередь, дал толчок развитию авантюрной пикарески; затем традиция любовно-приключенческих сюжетов породила во Франции XVII в. галантно-героический и любовно-психологический роман. XVIII в. положил начало роману экзотическому, а также сатирическому и бытовому (Г. Фильдинг, Т. Смолетт); ХІХ в. ознаменовался появлением романов романтического и мистического толка (немецкие романтики), а позднее оккультного (Ж. Санд), историческо-авантюрного (В. Скотт, А. Аюма, Г. Сенкевич), комического (Ч. Аиккенс, А. Аоде), уголовного и романы «приключений на суше и на море» (Благой, 1925).

Генетический подход, который позволил А. Благому описать жанровое развитие приключенческой литературы под видом авантюрного романа, до сих пор плодотворно используется многими учеными.

\section{КААССИФИКАЦИЯ ПРИКАЮЧЕНЧЕСКИХ ЖАНРОВ}

Современный приключенческий роман, по мнению большинства историков литературы, начинается со знаменитого «Робинзона Крузо» А. Аефо (1719). Однако, поскольку история романа вообще началась именно с его авантюрного вида, специфика приключенческого метажанра стала теоретически осмысляться только после появления такого направления, как реализм, т. е. приблизительно с середины XIX в. Таким образом, классификация метажанра делится на две части: историческую, описывающую его развитие до Аефо, и типологическую, охватывающую в основном литературу XIX-XXI вв. Если в первой части применяется генетический принцип, то во второй главным образом - тематический.

Историческое развитие приключенческой литературы описано достаточно полно. C началом XVIII в. приключенческая литература вступает в новую, современную фазу развития. Здесь классификация усложняется; общепринятой типологии жанров уже нет.

В отечественном литературоведении не существует работ, посвященных этой проблеме. Исследователи вынуждены ссылаться на «наиболее традиционное» представление, которым «является выделение следующих четырех подвидов приключенческой прозы: детективная литература, фантастическая литература, историческая приключенческая литература (к ней примыкает и литература о путешествиях), и детская литература» (Булычева, 2014: 1001). Это деление слишком общо для того, чтобы успешно применить его к жанровой классификации фэнтези.

В зарубежном литературоведении было предпринято несколько попыток обосновать типологию приключенческого метажанра. Например, автор работы «Семь типов приключенческой литературы: этиология большого жанра» М. Б. Грин использует в качестве дифференцирующего признака характер героя, подчеркивая, что именно роль персонажа в тексте определяет вид самого текста. Ученый пишет: «О характере главного героя можно сказать, что он “порождает" или по крайней мере определяет приключения, составляющие содержание книги» (Green, 1991: 21). М. Б. Грин выделя- 
ет несколько типовых героев и «порождаемых» ими текстов, которые служат как бы эталоном для определяемых жанров. Это Робинзон (робинзонада), авантюрист («Три мушкетера»), колонист (романы Ф. Купера), мститель (готический роман), бродяга (пикареска, или плутовской роман), скальд (романы о викингах) и преследуемый (триллер) (там же: 70).

Классификация, предложенная Аж. Кавелти в его известной работе «Приключение, тайна и любовная история», менее подробна, но более точна. За ее основание ученый принимает понятие «моральной фантазии». Моральная фантазия - это то представление о мире и долженствовании в нем, которое является комфортным для человека, при том что носитель фантазии осознает ее иллюзорность. Кавелти выделяет пять таких общечеловеческих ожиданий, которым соответствуют пять типов приключенческих текстов. Первый тип - это приключение в чистом виде, центром которого «является герой - один или их группа - преодолевающий препятствия и опасности и выполняющий некую важную нравственную миссию». «Возможно, основная моральная фантазия, скрытая в этом типе, - победа над смертью» (Cawelti, 1976: 39-40).

Второй тип (или жанр) - это женский эквивалент авантюрного текста, т. е. любовный роман. Его «моральная фантазия... заключается в том, что любовь всепобеждающа и неизменна, преодолевает все препятствия и трудности» (там же: 41-42).

Третий тип, выделяемый Кавелти, - тайна. В основе всех жанровых модификаций, базирующихся на этой моральной фантазии, лежит убеждение, что любая загадка имеет удовлетворительное рациональное объяснение.

Четвертый тип (или жанр) - мелодрама. «Этот тип имеет в центре моральную фантазию, состоящую в провозглашении коренной “правильности” миропорядка», пишет Кавелти (там же: 45). «Мелодрама показывает, как неоднозначность и трагедийность мира в конечном счете оборачиваются действием великодушного, ориентированного на человека морального порядка» (там же).

Последний - пятый - тип, выделяемый Кавелти, - это рассказы об иных существах и состояниях. Сюда относится то, что не может быть познано по определению в силу своей чуждости. Однако моральная фантазия утверждает, что человеку по силам если не победить, то хотя бы взять под контроль то, что ему иноприродно. К этому типу относится чистая готика, начиная со стокеровского романа о Аракуле.

Таким образом, вырисовывается достаточно стройная схема, которую можно принять за черновой набросок искомой классификации фэнтези.

\section{ЖАНРОВАЯ КААССИФИКАЦИЯ СОВРЕМЕННОГО ФЭНТЕЗИ}

Прежде всего, становится ясно, что фэнтези в силу своих мифологически-сказочных допущений синтезирует два основных вида приключений, а именно: приключение географическое и историческое. Поскольку действие фэнтезийной книги изначально разворачивается по большей части в вымышленных географических и исторических условиях, то роман «путешествий» вроде робинзонады или любой экзотической истории, сольется с историческим авантюрным романом, первым чистым видом которого был роман рыцарский. Таким образом, жанр героического фэнтези как бы «стягивает» обратно разветвившиеся жанровые подвиды, выделившиеся в XIX в., и возвращает нас к средневековому истоку современного романа, внося, однако, в фэнтезийную героику новые элементы. На этом направлении в русской литературе можно выделить 
соответственно: фэнтези «меча и магии» ( ХХранитель мечей» Н. Перумова; «Волкодав» М. Семеновой); историческое и псевдоисторическое фэнтези («Небеса ликуют» А. Валентинова, «Отблески Этерны» В. Камши); «воровское» или «разбойничье» фэнтези («Хроники Сиалы» А. Пехова), которое наследует пикареске и «разбойничьему» (в частности, пиратскому) роману. Это самое продуктивная, а следовательно, и основная ветвь фэнтези.

Аальше наблюдаются определенные ограничения. Аюбовный роман дает любовное фэнтези, которое по своему типу практически ничем не отличается от нефэнтезийной разновидности. Примером может послужить «Анахрон» В. Беньковского и Е. Хаецкой.

В области криминального романа мы видим зарождение детективного фэнтези, основоположником которого в западноевропейской литературе, очевидно, следует считать Р. Гаретта, а в русском фэнтези А. Пехова («Под знаком мантикоры», «Пересмешник»). Однако в криминальном жанре фэнтезийный принцип не может быть определяющим.

Готический роман с введением дополнительных допущений дает все разновидности «черного» фэнтези ( «Странствия Сенора» А. Аашкова, «Ночной смотрящий» О. Аивова), а научная фантастика - «научное» фэнтези или техномагию («Тайный Город» В. Панова).

И наконец, социально-приключенческий роман, действие которого разворачивается в современности, при появлении мифологически-сказочных посылок дает тот вид фэнтези, который в современной издательской практике принято называть городским (цикл «Аозоры» С. Аукьяненко).

Приведенная типология показывает, что собственно фэнтезийные жанры не обнаруживают существенной самостоятельности; все они являются дишь новым этапом в развитии единого приключенческого метажанра. Заметно, что наибольшая активность наблюдается на том направлении, где фэнтезийная предпосылка является органически-естественной. Напротив, любовная и криминальная линии изначально обладают другим набором интенций, и фэнтезийная составляющая не может выступить в них на первый план, не исказив тем самым природу жанрового саспенса. В этом смысле очень характерно, что сыщики в детективном фэнтези начиная с лорда Аарси у Р. Гарретта до Фернана де Суозы у А. Пехова по большей части лишены всяких магических способностей. С другой стороны, в готическом и фантастическом романе в отличие от чисто приключенческого фантастический элемент изначально настолько силен, что элементам фэнтези иной раз грозит просто затеряться среди других.

\section{ВЫВОДЫ}

Подводя итоги проведенной «генетико-типологической» классификации, можно сказать, что собственно фэнтези является закономерной стадией в развитии приключенческого метажанра в части тех его жанровых модификаций, которые именуются в широком плане географическим или историческим приключением, а также готического романа ужасов и научной фантастики.

\section{СПИСОК АИТЕРАТУРЫ}

Алексеев, С., Батшев, М. (1997) Фэнтези - развитие жанра в России // Книжное дело. № 1. C. 82-86. 
Афанасьева, Е. (2009) Жанр фэнтези: проблема классификации // Фантастика и технологии (памяти Станислава $\Lambda$ ема) : сб. материалов Международной научной конференции 29-31 марта 2007 г. Самара : Изд. дом «Раритет». 251 с. С. 86-93.

Благой, А. (1925) Авантюрный роман // Аитературная энциклопедия: Словарь литературных терминов : в 2 т. М. ; $\Lambda$. : ИзА-во $\Lambda$.А. Френкель. Т. 1. А - П. 576 стб. Стб. 3-10.

Булычева, В. П. (2014) Приключенческая литература: история изучения и жанровая природа // Фундаментальные исследования. № 8. С. 998-1002.

Вулис, А. 3. (1986) В мире приключений. Поэтика жанра. М. : Советский писатель. 384 с.

Каган, М. С. (1972) Морфология искусства. $\Lambda$. : Искусство. 440 с.

Ковтун, Е. Н. (1999) Поэтика необычайного. Художественные миры фантастики, волшебной сказки, утопии, притчи и мифа (На материале европейской литературы первой половины ХХ века). М. : ИзА-во МГУ. 308 с.

Невский Б. (2004) Жанры. Русское фэнтези [Электронный ресурс]// Мир фантастики. № 11. URL: http://mirf.ru/Articles/art342.htm [архивировано в WebCite] (дата обращения: 11.06.2015).

Шидфар, Р. (1997) Бесконечная история. Очерк развития зарубежной фэнтези // Книжное дело. № 9. С. 86-90.

Green, M. B. (1991) Seven types of adventure tale: An etiology of a major genre. University Park, PA : Penn State University Press. 244 p.

Cawelti, J. G. (1976) Adventure, mystery, and romance: Formula stories as art and popular culture. Chicago : University of Chicago Press. 336 p.

Аата поступления: 12.06 .2015 2.

\section{PLACING FANTASY LITERATURE WITHIN GENRE TAXONOMY OF ADVENTURE FICTION \\ I. V. LEBEDEV \\ (SHOLOKHOV Moscow StATE UNIVERSITY FOR THE HUMANITIES)}

The paper addresses the issue of genre attribution of today's Russian fantasy literature. The auth or attempts to build a taxonomy of fantasy genres upon their subject or themes, and upon artistic functions as suggested by M.S. Kagan, with a focus on the flaws of these approaches. Instead, the author suggests to use genetic-typological method based on tracing the evolution of adventure fiction as a whole. Since fantasy comes as the newest stage in the evolution of adventure literature, such an approach is the most relevant.

Modern fantasy literature combines both key types of adventure, geographical and historical, conflating a 'travel' novel of the Robinsonade with a historical adventure novel. Fantasy literature thus 'retracts' the outgrown genre subtypes. This trend is exemplified by the following movements in contemporary Russian literature: 'sword and sorcery' fantasy ("The Keeper of Swords" by N. Perumov; "Wolfhound" by M. Semyonova); historical and pseudo-historical fantasy ("Heavens Rejoice" by A. Valentinov; "Gleams of Aeterna" by V. Kamsha); and 'rogue' fantasy ("Chronicles of Siala" by A. Pekhov) which is derived from picaresque novel and piracy novel. Romance gives birth to romantic fantasy ("Anachron" by V. Benkovskiy and E. Khaetskaya); the field of crime literature can be linked to the forming of detective fantasy ("Under the Sign of Manticore" and "The Mockingbird" by A. Pekhov). Gothic novel gives rise to all sorts of 'dark' fantasy ("Senor's Wanderings" by A. Dashkov; "The Nightwatcher" by O. Divov) and science fiction to 'science' fantasy and steampunk ("The Clandestine City" by V. Panov). Finally, social adventure novel, with the introduction of mythopoeia, becomes what in modern publishing practice is known as urban fantasy (the "Watches" hexalogy by S. Lukyanenko).

A typological approach reveals that true fantasy subgenres have little originality of their own: each proves to be nothing more than a recent stage in the evolution of some branch of the whole adventure fiction meta-genre. Most rapid development happens where mythopoeia as a speculative device is organic and integral. On the contrary, romance and crime story traditions are originally endowed 
with another set of intentions, which does not allow the fantasy elements to dominate without ruining the structure of suspense natural of this or that genre.

Keywords: Russian fantasy literature, adventure fiction, genre, meta-genre, genre classification.

\section{REFERENCES}

Alekseev, S. and Batshev, M. (1997) Fentezi - razvitie zhanra v Rossii [Fantasy: The evolution of the genre in Russia]. Knizhnoe delo, no. 1, pp. 82-86. (In Russ.).

Afanasieva, E. (2009) Zhanr fentezi: problema klassifikatsii [Fantasy as a genre: The problem of classification]. In: Fantastika i tekbnologii (pamiati Stanislava Lema) [Science Fiction and Technologies (In the memory of Stanislaw Lem)] : Proceedings of the International academic conference, March 29-31, 2007. Samara, Raritet Publishing House. 251 p. Pp. 86-93. (In Russ.).

Blagoi, D. (1925) Avantiurnyi roman [Adventure Novel]. In: Literaturnaia entsiklopediia: Slovar' literaturnykb terminov [Literary encyclopedia: A handbook of literary terms] : in 2 vols. Moscow ; Leningrad, L. D. Frenkel's Publ. Vol. 1. 576 clmns. Clmns. 3-10. (In Russ.).

Bulycheva, V. P. (2014) Prikliuchencheskaia literatura: istoriia izucheniia i zhanrovaia priroda [Adventure fiction: History of research and genre nature]. Fundamental'nye issledovaniia, no. 8, pp. 998-1002. (In Russ.).

Vulis, A. Z. (1986) V mire prikliuchenii. Poetika zhanra [In the world of adventures. Poetics of genre]. Moscow, Sovetskii pisatel' Publ. 384 p. (In Russ.).

Kagan, M. S. (1972) Morfologiia iskusstva [The morphology of art]. Leningrad, Iskusstvo Publ. 440 p. (In Russ.).

Kovtun, E. N. (1999) Poetika neobychainogo: Khudozbestvennye miry fantastiki, volshebnoi skazki, utopii, pritchi i mifa (Na materiale evropeiskoi literatury pervoi poloviny XX veka) [Poetics of the incredible: The imaginary worlds of science fiction, fairy tale, utopia, parable and myth (The case of European literatures of the 1st half of the $20^{\text {th }}$ century)]. Moscow, Moscow State University Publ. 308 p. (In Russ.).

Nevskii, B. (2004) Zhanry. Russkoe fentezi [Genres. Russian fantasy fiction]. Mir fantastiki i fentezi, no. 11. [online]. Available at: http://mirf.ru/Articles/art342.htm [archived in WebCite] (accessed 11.06.2015). (In Russ.).

Shidfar, R. (1997) Beskonechnaia istoriia. Ocherk razvitiia zarubezhnoi fentezi [An endless history. A review of evolution of fantasy literature abroad]. Knizbnoe delo, no. 9, pp. 86-90. (In Russ.).

Green, M. B. (1991) Seven types of adventure tale: An etiology of a major genre. University Park, PA, Penn State University Press. 244 p.

Cawelti, J. G. (1976) Adventure, mystery, and romance: Formula stories as art and popular culture. Chicago, University of Chicago Press. viii, 336 p.

Submission date: 12.06.2015.

Иебедев Иван Владимирович - аспирант кафедры русской и зарубежной литературы Московского государственного гуманитарного университета им. М. А. Шолохова. Адрес: 111539, Россия, г. Москва, ул. 3-я Владимирская, д. 7. Тел.: +7 (495) 672-04-90. Эл. адрес: vaanya@yandex.ru. Научный руководитель - д-р филол. наук, проф. Н. А. Котовчихина.

Lebedev Ivan Vladimirovich, Postgraduate Student, Department of Russian and Foreign Literature, Sholokhov Moscow State University for the Humanities. Postal address: 7, 3rd Vladimirskaia St, 111539 Moscow, Russian Federation. Tel.: +7 (495)672-04-90. E-mail: vaanya@yandex.ru. Research advisor: Doctor of Philology, Prof. N. D. Kotovchikhina. 